\title{
O CINEMA EM CENA: UM DIÁLOGO ENTRE LINGUAGENS NA OBRA DE MANOEL DE OLIVEIRA
}

\author{
FILM IN SCENE: A DIALOGUE BETWEEN LANGUAGES IN THE WORK OF \\ MANOEL DE OLIVEIRA
}

\author{
Mariana Veiga Copertino \\ UNESP - Araraquara
}

\begin{abstract}
RESUMO: Centrado nessa concepção estética de Oliveira, o objetivo deste trabalho é analisar um de seus filmes baseados em textos literários - Meu Caso (Mon cas), produzido em 1986 e inspirado no drama homônimo de José Régio. Pretendemos identificar nele o diálogo entre literatura, teatro e cinema, considerando os aspectos da teatralidade presentes no filme. Buscaremos verificar a hipótese de que Manoel de Oliveira preza o uso dos elementos teatrais como forma de inovar o cinema, unindo as duas artes, teatro e cinema. Esperamos mostrar, deste modo, como é teatral a obra cinematográfica de Manoel de Oliveira.
\end{abstract}

PALAVRAS-CHAVE: Manoel de Oliveira, cinema, literatura

ABSTRACT: The objective of this paper is to analyze one of the films of Manoel de Oliveira, which is based on a literary text - My Case (Mon cas), produced in 1986 and based on the eponymous drama by José Regio. We intend to identify the dialogue between literature, theater and film, considering the aspects of theatricality present in the film. Seek to verify the hypothesis that Manoel de Oliveira appreciates the use of theatrical elements as a way to innovate cinema, combining the two arts, theater and cinema. Hope to show, therefore, as the film is theatrical work of Manoel de Oliveira

KEYWORDS: Manoel de Oliveira, film, literature

\section{INTRODUÇÃO}

Com 104 anos de idade, dos quais 78 são dedicados ao cinema, Oliveira tem 26 filmes de curta e média-metragem e 31 de longa-metragem, produzidos em Portugal, França, Itália, Suíça e Brasil. Tendo dado início à sua carreira em 1931 com o lançamento do documentário Douro, Faina Fluvial, Manoel de Oliveira atravessou o século $X X$, realizando pelo menos um filme por ano desde o princípio da década de 1980, quando lançou Francisca (1981). 


\section{Revista do SELL}

v. $4, \mathrm{n}^{\circ} .2$

ISSN: $1983-3873$

Adentrou ainda o século XXI, tendo produzido diversos filmes, longas e curtasmetragens, até o ano de 2012.

Observando o conjunto de suas produções, é possível afirmar que uma das características mais marcantes da obra de Manoel de Oliveira é a dedicação a utilizar textos literários como fonte para seus filmes. Esse cinema oliveiriano, vale dizer, também preza o uso de elementos teatrais, buscando, através desse artifício, aproximar a arte do cinema de outras artes, especialmente a do teatro, ao lado da literária e de outras que tanta importância têm no seu cinema como, por exemplo, a música e a pintura. Essa relação estreita que Manoel de Oliveira estabelece entre o cinema e outras artes, sobretudo o teatro, acaba por provocar um efeito estético totalmente característico: o distanciamento entre o espectador e a obra, a fim de mostrá-la efetivamente como uma obra de ficção.

Pensando nessa concepção estética de Manoel de Oliveira, o objetivo desse trabalho é analisar um de seus filmes baseados em textos literários Meu Caso , produzido em 1986 e inspirado no drama homônimo de José Régio. Pretendemos identificar nele aspectos da teatralidade, buscando verificar a hipótese de que Manoel de Oliveira preza o uso dos elementos teatrais como forma de inovar o cinema mundial, unindo as duas artes: Teatro e Cinema, mostrando quão teatral é a obra oliveiriana, ainda que cinematográfica.

\section{DOIS CASOS: A PEÇA E O FILME}

A peça, escrita em 1950, por José Régio aborda o tema da incomunicabilidade de uma forma bastante interessante: fazendo uso do recurso da metalinguagem para chamar a atenção do público. As próprias personagens são nomeadas como participantes de um espetáculo teatral; são chamadas: o Porteiro, a Actriz, o Autor e o Espectador, estando essas funções teatrais personificadas pela letra maiúscula. $O$ enredo consiste no seguinte: um Desconhecido, burlando a vigilância do porteiro, invade o palco minutos antes do inicio de uma comédia, reivindicando contar ao público o seu caso. A personagem garante a todos que é um caso excepcional, simbólico, que, 


\section{Revista do SELL}

v. $4, n^{\circ} .2$

ISSN: $1983-3873$

diferente de qualquer experiência banal que o espectador conhecesse, abordaria as profundezas inexploráveis do ser humano. Ele alega ter sido escolhido pelos deuses para comunicar uma mensagem divina. Ao final, o pano cai brusco e rápido sem que o tal Desconhecido consiga contar o seu caso, impedido e interrompido constantemente por casos ridículos e sem grandeza, segundo ele: o caso do Empregado, um pai de família que tem uma mulher paralítica e três filhos para sustentar; o da Atriz que desespera-se por desempenhar bem o papel que ela considera ser o primeiro decente de sua carreira e se frustra com a interrupção do Desconhecido; o do Autor que bajulara muitas pessoas a fim de ver sua peça ser encenada; e o de um Espectador que se irrita por ter ido ao teatro e precisar presenciar aquelas bobagens todas.

Manoel de Oliveira, ao adaptar essa obra dramática para o cinema ousa ainda mais ao desenvolver o tema da incomunicabilidade. $O$ realizador português divide seu filme em quatro partes e em cada uma delas apresenta esse tema de uma forma inusitada. A primeira parte consiste na reprodução fiel da peça de Régio em um palco de espetáculos. O elemento da metalinguagem já aparece logo no inicio quando uma câmera de filmagem é colocada em meio às poltronas para que fique claro ao espectador que aquilo é uma filmagem. Ao fim dessa interpretação a cortina do palco se fecha, como se o espetáculo tivesse acabado. É interessante ressaltar ainda, que nessa primeira fase do filme, Oliveira mantém fidedignidade ao texto de José Régio e isso é bastante significativo em se tratando de uma adaptação. Na segunda parte do filme, o cineasta reproduz a peça, em preto e branco ao som do monólogo "Fiasco II" de Samuel Beckett, presente no livro "Para acabar de novo e outros fiascos". O interessante nesse momento do filme é a intenção de Oliveira em reproduzir a técnica dos filmes mudos do início do século XX, e as cenas são mudas de fato, exceto pela voz de Henri Serre declamando o Fiasco II. O texto recitado acaba por refletir o que acontece visualmente nas cenas: a mudez e confusão das personagens que não conseguem se comunicar. As cenas mudas abusam da expressão facial dos atores, dos gestos, dos recuos e avanços nas cenas que marcam efetivamente a característica dos filmes mudos e a 


\section{Revista do SELL}

v. $4, n^{\circ} .2$

ISSN: $1983-3873$

impossibilidade de falar e ser ouvido na sociedade. Essa imagem da incomunicabilidade se constitui a partir da dissonância entre o que o espectador ouve e o movimento labial da fala muda das personagens.

A terceira repetição de Mon cas, consiste novamente na reprodução da peça de Régio, mas dessa vez a fala aparece descompassada com a imagem e as duas não se correspondem, causando ao espectador a impressão de ser uma Babel. Em determinado momento, o funcionário que segura a claquette e inicia cada uma das repetições, sobe ao palco, desmonta o objeto que tem em mãos e o transforma em uma mesa sobre a qual instala um projetor de imagens. Em uma tela ao fundo, são projetados vídeos de guerras e destruição. As personagens, no palco, viram-se de costas para o público e assistem a essa projeção. Ao cabo, elas retomam a sua discussão, do ponto em que pararam.

Por fim, a quarta parte do filme consiste na reprodução, não da peça de Régio, mas do texto do Livro de Jó, um dos sete livros Sapienciais do Antigo Testamento. Jó, segundo os escritos bíblicos, teve sua fé testada por Deus. $O$ demônio lançou-lhe diversos males terríveis que ele suportou com resignação sem perder a sua fé em Deus. Essa história bíblica aparece no filme como um desfecho que vem interar o tema principal, desenvolvendo duas questões que são lançadas ao público para reflexão: por que pessoas inocentes passam por tantos sofrimentos? Por que Deus permite que haja tanta iniquidade no mundo? A figura de Jó parece representar a solidão existencial do ser humano, resultado da incomunicabilidade.

O professor Antonio Preto refere-se a "Mon cas" como um filme teorema, realizado por Oliveira a fim de desenvolver uma espécie de tese, como um filme ensaístico, no qual o realizador reflete a respeito da peça de Régio e os questionamentos que ela propõe, mas também e, principalmente, sobre as relações entre cinema e teatro.

São inúmeros os elementos teatrais presentes em "Mon cas", a começar pelo fato de o local onde o filme todo se passa ser o palco de uma casa de espetáculos. Oliveira desenvolve toda uma reflexão a respeito da presença do teatro e do cinema coexistindo em um mesmo ambiente, desde o momento em 


\section{Revista do SELL}

v. $4, n^{\circ} .2$

ISSN: $1983-3873$

que nomeia cada uma das partes como répétition que do francês pode ser traduzida como repetição, mas também como ensaio, reforçando a sugestão de que o filme seria, de fato, um estudo a respeito dos temas abordados.

A metalinguagem, por sua vez, tem papel de suma importância na configuração dessa teatralidade oliveirana em "Mon cas". Manifestando-se em vários níveis, o filme apresenta uma combinação de metateatro e metacinema. A intenção de mostrar a obra de arte como ela realmente é, sem buscar criar nenhum tipo de ilusão, permite que o filme oscile entre a ficção e a meta-ficção criando o efeito de distanciamento, já proposto por Brecht, no teatro. O tempo todo os atores se dirigem ao público, fazendo perguntas ou desculpando-se pela confusão que ali acontece, além disso, uma das personagens da peça é justamente o espectador, que sai do meio da platéia para questionar as discussões ali representadas até então. A ostentação do artifício, em "Mon cas" é evidente e muito significativa para a dialética teatro/cinema do contexto da obra, como aponta o professor Antonio Preto.

O cinema ilumina o que há de simulacral do teatro: desconstruindo e reduplicando o artifício, dá a ver a construção teatral em toda a sua volumetria; o teatro desmascara o cinema: a representação frontal e o olhar para a câmara-espectador denunciam a mediação cinematográfica não sendo, pois, por acaso que é, precisamente, nos filmes que refletem sobre 0 teatro que Manoel de Oliveira produz, com maior insistência, a mise en scène do cinema dentro do cinema. (PRETO, 2009, p. 19)

Desde o momento em que o funcionário da equipe de cinema sobe ao palco e bate a claquette indicando que a próxima repetição está para começar, ou a queda da cortina do palco que quebra a possível ilusão que se havia criado até o momento, ou ainda, na representação do Livro de Jó, quando a figura de Deus representada por uma forte luz sobre as personagens e uma voz que ecoa por todo o espaço é desconstruída no momento em que a câmera mostra um holofote e um auto-falante. Aí, vemos mais uma vez o distanciamento brechtiano em ação. 


\section{Revista do SELL}

v. $4, \mathrm{n}^{\circ} .2$

ISSN: $1983-3873$

Pensando ainda nos diferentes níveis de metalinguagem presentes nessa obra oliveiriana, o meta-teatro que proporciona a quebra da ilusão ocorre claramente na cena em que a Actriz, na sua interpretação do caso sobre o qual é a trama da comediazinha, é interrompida pelo Desconhecido e sai da personagem para ser a Actriz, personagem da peça de Régio. Esse momento é bastante significativo, pois a câmera cinematográfica fecha o enquadramento em plano americano no rosto da atriz e embora haja outras atuações na cena, o foco não se altera. Enquanto ouvimos ao fundo a voz do desconhecido criticando a banalidade do caso de fútil impasse amoroso, vemos a transformação da personagem da comediazinha em Actriz (que na realidade, não deixa de ser uma personagem também, da peça de Régio). Oliveira se preocupou, nesse momento do filme em deixar claro para o leitor essa transformação, essa quebra da ilusão, mantendo o enquadramento o tempo todo, até que a mulher tenha um surto e comece a discutir com os dois homens em cena, saindo totalmente da personagem que interpretava. Nessa sequência, vemos a surpresa estampada no rosto da Actriz, que aos poucos vai se transformando em irritação profunda, até culminar numa explosão de raiva por estarem estragando a sua estréia como protagonista.

Outra característica do teatro épico presente no filme de Oliveira é a presença de fortes elementos da narrativa. Isso acontece, com destaque, duas vezes ao longo da película. A primeira delas é durante a terceira repetição da peça "Meu caso", quando o cineasta faz uso do que o renomado cineasta Sergei Eisenstein chamaria de montagem intelectual, "a montagem não de sons atonais geralmente fisiológicos, mas de sons e atonalidades de um tipo intelectual, isto é, conflito-justaposição de sensações intelectuais associativas" (EISENSTEIN, 2002, p. 86). Enquanto todos os personagens encontram-se em uma discussão sem sentido, na qual absolutamente ninguém se compreende, ocorre a projeção de algumas cenas no fundo do palco; isso parece chamar a atenção das personagens e conduzir a atenção dos espectadores, também. A princípio, a justaposição das cenas que se associa pela temática e compõe um sentido mais amplo, pode ser considerada como uma montagem métrica, porém, não podemos deixar de entendê-las como uma 


\section{Revista do SELL}

v. $4, \mathrm{n}^{\circ} .2$

ISSN: $1983-3873$

montagem intelectual, também. A sequência mostra cenas de guerra, morte, destruição, chacinas, genocídios, desastres ambientais e uma série de outros fatos terríveis que evidenciam os crimes cometidos pelo homem contra si mesmo e contra a natureza. Nessa montagem intelectual vê-se a condição do mundo contemporâneo e o espectador é levado a compreender, intelectualmente, que o motivo desses desastres é fato de o ser humano não conseguir entender a si mesmo, remetendo ao tema da incomunicabilidade desenvolvida ao longo do filme todo.

\section{CONSIDERAÇÕES FINAIS}

Manoel de Oliveira encerra seu filme magistralmente quando, ao final da história bíblica representada, durante os festejos da recuperação de Jó, alguns atores adentram o palco carregando uma réplica da Mona Lisa de Leonardo Da Vinci, como forma de demonstrar que a arte enquanto linguagem e forma de expressão, pode ser um caminho para o fim da incomunicabilidade pós moderna. A finalização do filme consiste no foco da câmera enquadrando a imagem da pintura, e lentamente se abrindo, nos mostrando a Mona Lisa, através de um monitor de vídeo que é parte do equipamento de filmagem, assim, da mesma forma que se iniciou, o filme se encerra com a metalinguagem do cinema e do teatro, relembrando ao público que aquilo não é real e precisa ser analisado e questionado. Dessa forma, é possível aproximar Oliveira de Brecht, no sentido de que ambos, ainda que não com o mesmo engajamento, levam o seu espectador a refletir criticamente a respeito daquilo que é tratado na representação.

\section{REFERÊNCIAS BIBLIOGRÁFICAS}

EISENSTEIN, Sergei. A forma do filme. Apresentação, notas e revisão técnica de José Carlos Avellar. Tradução de Teresa Ottoni. Rio de Janeiro: Jorge Zahar Ed., 2002.

PRETO, António. Manoel de Oliveira: palavra imagem. Suplemento literário, Belo Horizonte, n. 1317, fev. 2009, p. 18-21. Acesso on line: http://www.cultura.mg.gov.br/arquivos/SuplementoLiterario/File/sl-fevereiro2009.pdf 


\section{BIBLIOGRAFIA CONSULTADA}

AUMONT, Jacques. Dicionário teórico e crítico de cinema/ Jacques Aumont, Michel Marie; tradução Eloisa Araújo Ribeiro. Campinas: Papirus, 2003

BRECHT, Bertolt. Estudos sobre teatro. Tradução de Fiama Pais Brandão. 2ed. Rio de Janeiro: Nova Fronteira, 2005

EISENSTEIN, Sergei. O sentido do filme. Apresentação, notas e revisão técnica de José Carlos Avellar.. Rio de Janeiro: Jorge Zahar Ed., 2002.

JUNQUEIRA, Renata Soares (Org.).Manoel de Oliveira: uma presença. Estudos de literatura e cinema. São Paulo: Editora Perspectiva, 2010.

PRETO, António. Manoel de Oliveira: o cinema inventado à letra. Porto: Fundação Serralves, 2008.

SZONDI, Peter. Teoria do drama moderno (1880-1950). Trad. de Luiz Sérgio Repa. São Paulo: Cosac \& Naify, 2001.

XAVIER, Ismail (Org.). A experiência do cinema: antologia. 1 ed. Rio de Janeiro: Edições Graal; Embrafilme, 1983. (Arte e Cultura, 5).

XAVIER, Ismail. 0 discurso cinematográfico: a opacidade e a transparência. 4 ed. São Paulo: Paz e Terra, 2008. 